\title{
Efficacy and Effects of Parenteral Pethidine or Meptazinol and Regional Analgesia for Pain Relief during Delivery. A Comparative Observational Study
}

\author{
Effektivität und Auswirkungen von parenteralem Pethidin oder Meptazinol und Regionalanalgesie
} zur Schmerzlinderung unter der Geburt. Eine vergleichende Beobachtungsstudie

Authors

Affiliations
J. Singer ${ }^{1}$, A. Jank ${ }^{2}$, S. Amara ${ }^{2}$, P. D. H. Stepan ${ }^{2}$, U. Kaisers ${ }^{1}$, C. Hoehne ${ }^{1}$

${ }^{1}$ Department of Anesthesiology and Intensive Care Medicine, University Hospital of Leipzig, Leipzig, Germany

2 Department of Obstetrics, University Hospital of Leipzig, Leipzig, Germany

\begin{abstract}
Key words
- regional anesthesia

- obstetrics

pain therapy

Schlüsselwörter

- Regionalanästhesie

- Geburtsanalgesie

- Geburtshilfe

- Schmerztherapie
\end{abstract}

Deutsche Version unter: http://dx.doi.org/ 10.1055/s-0042-111009

received 24.8.2015 revised 13.5.2016 accepted 22.6.2016

\section{Bibliography}

Dol http://dx.doi.org/

10.1055/s-0042-111009

Geburtsh Frauenheilk 2016; 76:

964-971 @ Georg Thieme

Verlag KG Stuttgart - New York . ISSN 0016-5751

\section{Correspondence}

Prof. Claudia Hoehne, MD

University Hospital of Leipzig

Department of Anesthesiology and Intensive Care Medicine

Liebigstraße 20

04103 Leipzig

Germany

claudia.hoehne@

medizin.uni-leipzig.de

\section{Abstract \\ $\nabla$}

Background: Peripartum anesthesia may consist of parenteral opioids and/or regional analgesia. There is only limited data in the literature comparing both methods in daily obstetric practice. This observational study investigated the opioids pethidine and meptazinol as well as regional analgesics with regard to their administration, efficacy, side effects and subjective maternal satisfaction with therapy. The rates of secondary regional analgesia administration after administration of the respective opioid served as a means of evaluating treatment.

Methods: This study collected data on pain management during vaginal delivery in a German university hospital over a twelve month period. Severity of pain was measured intrapartum using a numerical rating scale. Maternal, neonatal and delivery-related data were obtained postpartum from the clinical records and from the mothers using a questionnaire.

Results: The study is based on data obtained from 449 deliveries. Pain relief achieved by the administration of pethidine and meptazinol was similarly low; maternal satisfaction with the respective therapy was high. Meptazinol was usually administered intravenously ( $83 \%$ vs. $6 \%$; $\mathrm{p}<0.001$ ), repeatedly $(27 \%$ vs. $6 \%$; p < 0.001$)$ and closer to the birth $(1.9 \pm 2.7 \mathrm{~h}$ vs. $2.6 \pm 2.8 \mathrm{~h}$; $\mathrm{p}<0.05)$ compared to pethidine. Secondary regional analgesia was more common after the administration of pethidine ( $16 \%$ vs. $8 \%$; $\mathrm{p}<0.05$ ). Regional analgesia resulted in greater pain relief compared to opioid therapy (78\% vs. $24 \%$ after $30 \mathrm{~min}$; $\mathrm{p}<0.001)$ and was associated with longer times to delivery $(7.6 \pm 2.5 \mathrm{~h}$ vs. $5.7 \pm 2.5 \mathrm{~h}$; $\mathrm{p}<0.001)$ and higher levels of maternal satisfaction with therapy ( $6.1 \pm 1.2$ vs. $4.8 \pm 1.6$ on a 7 -point scale; $\mathrm{p}<0.001)$.

Conclusion: In daily clinical practice, meptazinol can be adapted more readily to changes during

\section{Zusammenfassung \\ $\nabla$}

Hintergrund: Parenterale Opioide und Regionalanalgesie stellen mögliche peripartale Analgesiemethoden dar. In der Literatur liegen wenige Daten zum Vergleich der beiden Verfahren im geburtshilflichen Alltag vor. Diese Beobachtungsstudie untersucht die Opioide Pethidin und Meptazinol sowie Regionalanalgesie hinsichtlich Handhabung, Effektivität, Nebenwirkungen und subjektiver maternaler Therapiezufriedenheit. Die Rate sekundärer Regionalanalgesien nach jeweiliger Opioidgabe dient der Therapiebeurteilung.

Methoden: Im 12-monatigen Studienzeitraum wurden Daten vaginaler Geburten mit entsprechenden Schmerztherapien an einem deutschen Universitätsklinikum erfasst. Die intrapartale Schmerzstärke wurde mittels numerischer Ratingskala gemessen. Mutter-, kind- und geburtsbezogene Daten wurden postpartal aus der klinischen Dokumentation und von den Müttern anhand eines Fragebogens erhoben.

Ergebnisse: Die Studie umfasst Daten von 449 Entbindungen. Die Schmerzlinderung durch Pethidin und Meptazinol ist vergleichbar gering, die maternale Therapiezufriedenheit jeweils gut. Meptazinol wird häufiger intravenös (83 vs. 6\%; $\mathrm{p}<0,001$ ) und repetitiv (27 vs. $6 \%$; $\mathrm{p}<0,001$ ) sowie in geringerem Abstand zur Geburt verabreicht $(1,9 \pm 2,7 \mathrm{~h}$ vs. $2,6 \pm 2,8 \mathrm{~h} ; \mathrm{p}<0,05)$ als Pethidin. Sekundäre Regionalanalgesien sind häufiger nach Pethidingabe (16 vs. $8 \%$; $p<0,05$ ). Regionalanalgesie bewirkt eine stärkere Schmerzlinderung als Opioidtherapie (78 vs. $24 \%$ nach 30 min; $p<0,001$ ) bei längerem Geburtsverlauf $(7,6 \pm 2,5$ h vs. $5,7 \pm 2,5 \mathrm{~h} ; \mathrm{p}<0,001)$ und höherer maternaler Therapiezufriedenheit $(6,1 \pm 1,2$ vs. 4,8 $\pm 1,6$ auf einer 7-Punkte-Skala; $\mathrm{p}<0,001$ ).

Schlussfolgerung: Im klinischen Alltag kann Meptazinol besser an den Geburtsverlauf adaptiert werden und macht weniger sekundäre Re- 
birth and requires less secondary analgesia. Regional neuraxial analgesia was found to be an efficacious and safe way of managing labor pain. gionalanalgesien notwendig. Regionalanalgesie zeigt sich in der Praxis als effektive und sichere Wehenschmerztherapie.

\section{Introduction}

One of the biggest challenges in routine anesthesiology and obstetric practice is achieving pain relief during delivery which is both satisfactory and safe. The most common methods used for pain relief during delivery are regional anesthesia (RA) using a spinal or epidural analgesic and parenteral opioid therapy, in particular pethidine and meptazinol [1]. The opioids have been criticized because of their limited analgesic efficacy, the associated side effects such as nausea, fatigue, and the potential for maternal and neonatal respiratory depression $[2,3]$. The analgesic superiority of regional analgesia over parenteral opioid therapy has been sufficiently documented elsewhere in randomized studies [4,5]. Higher levels of maternal satisfaction with pain management are usually reported for RA [6,7], although a recent meta-analysis found that results for RA were comparable to those for opioids [8]. It has been suggested that the administration of RA results in prolonged labor and higher numbers of surgical vaginal deliveries [8]. The secondary cesarean section rate is not affected by RA $[8,9]$.

Pethidine is the most commonly used opioid in the obstetric setting [1]. It acts mainly through the $\mu 1$ and $\mu 2$ opioid receptors. The active metabolite norpethidine crosses the placenta and is excreted into breast milk. The recommended method of administration is through intramuscular administration [10]. The individual dose for adults is $25-150 \mathrm{mg}$ when administered intramuscularly (IM) and $50 \mathrm{mg}$ with intravenous (IV) administration [11]. It reaches its maximum effect after 30-40 minutes and can be re-administered after 3-6 hours [12]. Its elimination half-life in neonates is around 23 hours because of the neonate's immature elimination pathways, while in adults the elimination halflife of pethidine is only 3 hours [13].

The opioid analgesic meptazinol is increasingly being used in obstetrics. It acts through the $\mu 1$ opioid receptor and central cholinergic neurotransmission and can be administered either intramuscularly or intravenously, reaching its maximum effect after 30-60 min. The standard individual dose for an adult is IM 75$100 \mathrm{mg}$ and IV $50-100 \mathrm{mg}$. Repeat administration is possible after $2-4 \mathrm{~h}$ [11]. The elimination half-life is around 3.5 hours in neonates and 2 hours in adults [12,14].

In the literature the analgesic effect of both opioids is usually classified as equivalent and as generally low, although sometimes meptazinol is judged to have a better side effects profile with less neonatal respiratory depression $[15,16]$. Very few studies have looked at maternal satisfaction with parenteral opioid therapy and, on investigation, the opioids are generally found to be comparable [17].

A comprehensive evaluation of pain management therapies should include the effects of therapy on maternal birth experience, as it does not necessarily depend on the extent of pain relief [18]. In a parallel study, a cooperating study group therefore examined the impact of systemic opioid therapy and regional analgesia on women's birth experiences in the same observational period [19].

The purpose of this study was to compare the opioid analgesics pethidine and meptazinol in clinical practice in a level- 1 perinatal center with regard to administration, pain relief, side effects profile and maternal satisfaction with therapy in an observational study. The rates for additional administration of analgesics, in particular, the rates for secondary regional neuraxial analgesics administered following administration of one of the opioids served as an additional quality criterion for the respective opioid therapy.

\section{Materials and Method \\ $\nabla$}

\section{Study design}

This study was a prospective, single-center, non-interventional, observational study. After receiving the approval of the local ethics committee (AZ036-12-23012012) on February 7th, 2012, the twelve months' observation period was started on March 1st, 2012 in the Department of Obstetrics of Leipzig University Hospital. In the first six months, only pethidine was used for peripartum opioid therapy; in the last six months meptazinol was exclusively used for peripartum opioid therapy. Administration of neuraxial RA was always possible at any time over the entire study period.

\section{Inclusion and exclusion criteria}

Adult women who had delivered spontaneously or had a surgical vaginal delivery in the $\geq 37$ th week of gestation and who received pethidine or meptazinol and/or RA were included in the study. Patients who did not consent and patients who required secondary cesarean section were excluded from the study. In accordance with the standards used in non-interventional observational studies, the individual decisions for therapy were based on established medical practice and on a consensus between the physician or midwife and the informed patient.

\section{Dosages of intrapartum medication}

There were no fixed dosages for peripartum medications. Depending on the individual decisions of the clinicians, pethidine was usually administered at a dose of $100 \mathrm{mg}$ IM (84.6\%), followed by $10-15 \mathrm{mg}$ IV (8.3\%), and $50 \mathrm{mg}$ IM (5.3\%). In most cases meptazinol was administered at a dose of $100 \mathrm{mg}$ IV (44.5\%). Other common dosages were meptazinol $50 \mathrm{mg}$ IV (27.7\%), $100 \mathrm{mg}$ IM (13.4\%) and 25-40 mg IV (9.9\%). Other doses were only administered in isolated cases.

In $83.9 \%$ of cases, RA consisted of combined spinal-epidural anesthesia (CSE) and in $16.1 \%$ of cases of peridural anesthesia (PDA), with intermittent bolus administration of the respective medication. Adrenalin and lidocaine were generally administered in test doses (99.4 and 97.6\%). 82.1\% of patients who received RA were given sufentanil, initially administered intrathecally at a dose of $5-10 \mu \mathrm{g}$; in $7.7 \%$ of cases, the same dose was administered by epidural injection. $19.7 \%$ of patients who received RA were given an initial epidural dose of ropivacaine $5-20 \mathrm{mg}$. $17.9 \%$ of RA patients received subsequent epidural injections of sufentanil 5-20 $\mu \mathrm{g}$ and $35.7 \%$ of RA patients had subsequent injections of ropivacaine $10-20 \mathrm{mg}$. 
Table 1 Comparison of groups with respect to demographic data, patient history and clinical parameters (t-test for independent samples, $X^{2}$-test and Fisher's exact test).

\begin{tabular}{|c|c|c|c|c|c|c|c|}
\hline & \multicolumn{2}{|l|}{$\begin{array}{l}\text { Pethidine } \\
(n=157)\end{array}$} & $\begin{array}{l}\text { Meptazinol } \\
(n=162)\end{array}$ & \multicolumn{2}{|c|}{$\begin{array}{l}\text { Opioid monotherapy } \\
(\mathrm{n}=\mathbf{2 8 1})\end{array}$} & $\begin{array}{l}\text { Primary RA } \\
(n=130)\end{array}$ & $\begin{array}{l}\text { Secondary } \\
\text { RA }(n=38)\end{array}$ \\
\hline Age in years $(M \pm S D)$ & \multicolumn{2}{|l|}{$29.2 \pm 5.2$} & $29.4 \pm 5.4$ & \multicolumn{2}{|l|}{$29.5 \pm 5.3$} & $28.9 \pm 5.3$ & $27.8 \pm 5.1$ \\
\hline Height in $\mathrm{m}(\mathrm{M} \pm \mathrm{SD})$ & \multicolumn{2}{|c|}{$1.67 \pm 0.06$} & $1.67 \pm 0.06$ & \multicolumn{2}{|c|}{$1.67 \pm 0.06$} & $1.68 \pm 0.07$ & $1.67 \pm 0.05$ \\
\hline BMI prior to pregnancy $(M \pm S D)$ & \multicolumn{2}{|l|}{$23 \pm 4$} & $23 \pm 5$ & \multicolumn{2}{|l|}{$23 \pm 4$} & $23 \pm 4$ & $26 \pm 7$ \\
\hline BMI at birth $(\mathrm{M} \pm \mathrm{SD})$ & \multicolumn{2}{|l|}{$28 \pm 4$} & $28 \pm 5$ & \multirow{2}{*}{\multicolumn{2}{|c|}{$\begin{array}{c}28 \pm 4 \\
39.8 \pm 1.1\end{array}$}} & $29 \pm 5$ & $31 \pm 7$ \\
\hline Week of gestation $(\mathrm{M} \pm \mathrm{SD})$ & $40.0 \pm 1.0$ & $\leftarrow p=0.02 \rightarrow$ & $39.7 \pm 1.1$ & & & $39.9 \pm 1.2$ & $40.2 \pm 1$ \\
\hline Primipara (\%) & \multicolumn{2}{|c|}{64} & 63 & 61 & $\leftarrow p=0.003 \rightarrow$ & 76 & 79 \\
\hline High-risk pregnancy ${ }^{1} \%$ ) & \multicolumn{2}{|l|}{75} & 81 & \multicolumn{2}{|l|}{77} & 84 & 92 \\
\hline \multicolumn{8}{|l|}{ Specific pregnancy risks (\%) } \\
\hline - S/P cesarean section & 8 & $\leftarrow p=0.003 \rightarrow$ & 1 & \multicolumn{2}{|l|}{5} & 8 & 5 \\
\hline - breech presentation & \multicolumn{2}{|l|}{1} & 1 & 1 & $\leftarrow p=0.03 \rightarrow$ & 5 & 0 \\
\hline \multicolumn{8}{|l|}{ Birth (\%) } \\
\hline - spontaneous & \multicolumn{2}{|l|}{89} & 92 & \multicolumn{2}{|l|}{89} & 93 & 97 \\
\hline $\begin{array}{l}\text { surgical vaginal delivery } \\
\text { (forceps delivery or vacuum extraction) }\end{array}$ & \multicolumn{2}{|l|}{11} & 8 & \multicolumn{2}{|l|}{11} & 7 & 3 \\
\hline Induced birth ${ }^{2}(\%)$ & 34 & $\leftarrow p=0.04 \rightarrow$ & 24 & 26 & $\leftarrow p<0.001 \rightarrow$ & 59 & 53 \\
\hline Birth complications ${ }^{3}(\%)$ & \multicolumn{2}{|l|}{65} & 70 & \multicolumn{2}{|l|}{68} & 73 & 66 \\
\hline
\end{tabular}

${ }^{1}$ High-risk pregnancy according to the criteria of the German Maternity Guidelines, ${ }^{2}$ Oxytocin, misoprostol or Prepidil gel, ${ }^{3}$ Premature rupture of membranes, nuchal cord, green amniotic fluid, pathological CTG, uterine atony, other complications.

\section{Data collection}

Data collection was done in three steps. During the birth, the midwife asked the parturient patient when administering the opioid about the intensity of the pain she was experiencing prior to the therapeutic intervention and at 30 and 60 minutes after the intervention using an eleven point numerical rating scale (NRS0, 30 and 60; values ranged from $0=$ "no pain" to $10=$ "strongest imaginable pain"). If a neuraxial RA block was placed, the anesthesia nurse similarly asked the parturient patient about the intensity of the pain she was experiencing prior to the therapeutic intervention and at 30 and 60 minutes after the intervention using the same numerical rating scale described above. Maternal, neonatal and obstetric data were obtained from patient records, the protocol of the birth and the hospital's own electronic documentation programs. Data recorded included the administration and doses of any analgesics, birth complications, any administration of oxytocin for the induction or stimulation of labor, the rate of surgical vaginal deliveries, the duration of the birth, i.e., the duration from the start of the early stage of labor until complete delivery of the placenta, and the duration of analgesia from the first anesthetic intervention till the birth. The neonatal outcome was assessed using the parameters "Apgar score" (at one, five and ten minutes postnatally), umbilical cord arterial $\mathrm{pH}$, postnatal monitoring, and respiratory assistance. After the birth, patients were given a questionnaire which they were requested to complete within 24-72 hours post partum. The questionnaire recorded maternal satisfaction with the therapeutic intervention using a 7-point scale (from 1 = "not satisfied at all" to 7 = "entirely satisfied"). The women were also asked about nausea and emesis during the birth, their success in breastfeeding up to that point, their preparations for the birth, and their subjective attitude to the pain of giving birth. Postpartum data collection was also done in those cases where the intrapartum assessment of the pain was partially or entirely lacking, for example because of staff shortages or because the birth had ended within the onehour observation period.

\section{Statistical analysis}

Patients were divided into groups according to the analgesia method used and the aspect being investigated. Data were analyzed descriptively with standard univariate testing. The level of significance was $5 \%$. $\mathrm{X}^{2}$-test, Fisher's exact test and t-test for independent or paired samples were used, depending on the type of sample and on the aspect being investigated. Non-normally distributed samples of $n<30$ were analyzed using Mann-Whitney U-test and Wilcoxon signed rank test. Pain relief obtained by different therapeutic methods over time and in comparison were analyzed using multivariate analysis of variance with repeated measures. Various patient characteristics were also analyzed using binary logistic regression to determine how much they increased the probability or risk of the patient requiring RA. To do this, the total study population was analyzed using $\mathrm{X}^{2}$-test to determine the factors which were found to be present significantly more often with RA patients. All of these factors were subsequently included in the multivariate regression analysis.

\section{Results}

$\nabla$

A total of 449 patients were included in the observational study. 157 women were given pethidine (35\%), 162 women received meptazinol (36\%), and 168 women had regional analgesia (37\%). The last group was subdivided into 130 patients who only had RA (primary RA, 29\%), and 38 patients who had regional analgesia after receiving opioid therapy previously (secondary RA, 8\%). - Table 1 shows the comparison between groups with regard to medical history, demographic factors and clinical parameters.

\section{Clinical administration of pethidine and meptazinol}

Pethidine was usually administered as an intramuscular injection (94\%) and meptazinol usually as an intravenous injection (83\%) $(\mathrm{p}<0.001)$. The mean total opioid dose for a single birth was comparable for pethidine and meptazinol, with a mean dose of $99.8 \mathrm{mg}$ for pethidine and a mean dose of $95.3 \mathrm{mg}$ for meptazinol $(p=0.194)$. Meptazinol was administered repeatedly ( $\geq$ two 
Table 2 Pain relief obtained with the respective opioid therapy over time; comparison of pethidine with meptazinol (multivariate analysis of variance with repeated measures).

\begin{tabular}{|c|c|c|c|c|c|c|c|c|c|}
\hline & \multicolumn{3}{|c|}{ Pethidine, 1st dose } & \multirow{2}{*}{$\begin{array}{l}\text { Relative decrease } \\
\text { in pain scores }\end{array}$} & \multicolumn{3}{|c|}{ Meptazinol, 1st dose } & \multirow{2}{*}{$\begin{array}{l}\text { Relative decrease } \\
\text { in pain scores }\end{array}$} & \multirow{2}{*}{$\begin{array}{l}\text { Comparison } \\
\text { between groups }\end{array}$} \\
\hline & $\mathbf{n}$ & $\mathrm{M} \pm \mathrm{SD}$ & $\begin{array}{l}\text { Effect } \\
\text { over time }\end{array}$ & & $\mathbf{n}$ & $M \pm S D$ & $\begin{array}{l}\text { Effect } \\
\text { over time }\end{array}$ & & \\
\hline NRSO & 46 & $8.3 \pm 1.2$ & & & 64 & $8.2 \pm 1.4$ & & & $p=0.577$ \\
\hline NRS30 & 46 & $6.7 \pm 2.1$ & $p<0.001$ & $19 \%$ & 64 & $6.0 \pm 2.0$ & $p<0.001$ & $27 \%$ & \\
\hline NRS60 & 46 & $6.9 \pm 2.6$ & & $-3 \%$ & 64 & $7.3 \pm 2.1$ & & $-22 \%$ & \\
\hline
\end{tabular}

Table 3 Pain relief obtained with the therapy over time; comparison of opioid monotherapies with regional anesthesia (multivariate analysis of variance with repeated measures).

\begin{tabular}{|c|c|c|c|c|c|c|c|c|c|}
\hline & \multicolumn{3}{|c|}{ Opioid monotherapy, 1st dose } & \multirow{2}{*}{$\begin{array}{l}\text { Relative decrease } \\
\text { in pain scores }\end{array}$} & \multicolumn{3}{|c|}{ Primary RA } & \multirow{2}{*}{$\begin{array}{l}\text { Relative decrease } \\
\text { in pain scores }\end{array}$} & \multirow{2}{*}{$\begin{array}{l}\text { Comparison } \\
\text { between groups }\end{array}$} \\
\hline & $\mathbf{n}$ & $M \pm S D$ & $\begin{array}{l}\text { Effect } \\
\text { over time }\end{array}$ & & $\mathbf{n}$ & $M \pm S D$ & $\begin{array}{l}\text { Effect } \\
\text { over time }\end{array}$ & & \\
\hline NRSO & 97 & $8.2 \pm 1.3$ & & & 94 & $8.7 \pm 1.3$ & & & $p<0.001$ \\
\hline NRS30 & 97 & $6.2 \pm 2.1$ & $p<0.001$ & $24 \%$ & 94 & $1.9 \pm 2.3$ & $p<0.001$ & $78 \%$ & \\
\hline NRS30 & 97 & $7.1 \pm 2.3$ & & $-15 \%$ & 94 & $2.7 \pm 2.6$ & & $-42 \%$ & \\
\hline
\end{tabular}

times) in $27 \%$ of cases, while pethidine was only administered repeatedly in $6 \%$ of cases $(p<0.001)$. The final dose of meptazinol was administered at a significantly shorter interval to the birth $(1.9 \pm 2.7 \mathrm{~h})$ compared to the final dose of pethidine, which was administered $2.6 \pm 2.8$ hours prior to the birth $(p<0.05)$. If an opioid was administered repeatedly, the mean interval between two opioid doses was $5.2 \pm 3.7$ hours for pethidine compared to $1.6 \pm 1.4$ hours for meptazinol $(\mathrm{p}<0.001)$.

\section{Pain relief with pethidine and meptazinol}

On the 11-point rating scale, the mean severity of pain experienced immediately before receiving the initial opioid dose (NRS0) for all patients given opioid therapy was $8.2 \pm 1.3$ prior to receiving pethidine and $8.5 \pm 1.2$ prior to receiving meptazinol. - Tables 2 and 3 show the pain relief obtained with the two opioids over time and compare the two. Only patients who provided information about the intensity of pain experienced at each of the three time points were included in the analysis. The number of cases is therefore lower in this analysis compared to the total number of samples.

The tables show that both opioids achieved statistically comparable decreases in the intensity of pain $(p=0.577)$. However, pain relief over time differed significantly between the two opioids ( $p<0.001$ ). In the first 30 minutes after administration pethidine reduced pain by an average of 1.6 points on the scale (19\%); meptazinol reduced pain by an average of 2.2 points (27\%). Over a period of 30 to 60 minutes the pain increased again by 0.2 points $(3 \%)$ in women taking pethidine and by 1.3 points ( $22 \%$ ) in women taking meptazinol. Analysis using paired t-test showed that pain increased significantly more with meptazinol over this period $(\mathrm{p}<0.01)$.

\section{Maternal and neonatal outcomes after pethidine and meptazinol}

- Table 4 compares the two opioids with regard to duration of the birth, side effects, neonatal outcomes and maternal satisfac- tion with pain relief therapy. Postnatal umbilical cord arterial $\mathrm{pH}$ was significantly lower $(\mathrm{p}<0.01)$ in children born to women who had received pethidine compared to children whose mothers had received meptazinol. All other parameters were comparable for the two opioids.

\section{Rate of secondary regional anesthesia}

The rate of secondary RA administration after prior administration of pethidine was $16 \%(n=25)$ and thus higher compared to the rate of secondary RA after meptazinol which was $8 \%(n=13)$ $(p=0.029)$. $\bigcirc$ Table 5 shows the results of multivariate regression analysis of all relevant RA-promoting factors identified in our pool of data using $\mathrm{X}^{2}$-test. The odds ratio reflects the increased likelihood or increased risk for RA administration depending on specific parameters and indicates the existing probability for RA. With pethidine therapy, the risk for RA was more than twice as high $(\mathrm{OR}=2.4)$ compared to meptazinol therapy $(\mathrm{p}=0.046)$. A birth of more $>7$ hours was associated with a 9.9-fold higher risk for RA ( $p<0.001$ ), while medical induction of labor increased the risk 5.4-fold ( $p<0.001$ ). Factors which were found to be less relevant for RA administration were "high maternal BMI (>29) at the time of birth", "primiparity", "the belief of the parturient woman that painless birth was desirable", and "attending antenatal classes".

\section{Pain relief with opioid monotherapy} and regional analgesia

Administration of regional analgesia was the primary pain relief therapy in $77 \%$ of cases and the secondary pain relief therapy in $23 \%$. The intrapartum pain prior to therapy (NRS0) was comparable for opioid monotherapy (pethidine or meptazinol without secondary RA; $\mathrm{n}=281$ ) and primary $\mathrm{RA}$, with pain evaluated as $8.4 \pm 1.2$ prior to opioid monotherapy and $8.6 \pm 1.3$ prior to RA on the 11-point numerical rating scale. Tables 2 and $\mathbf{3}$ show the results for pain intensity experienced with the respective therapies over time and in comparison. This analysis again only 
Table 4 Maternal and neonatal outcomes following pethidine and meptazinol monotherapy; n.s. = not significant.

\begin{tabular}{|c|c|c|c|}
\hline & $\begin{array}{l}\text { Pethidine monotherapy } \\
(\mathrm{n}=132)\end{array}$ & $\begin{array}{l}\text { Meptazinol monotherapy } \\
(\mathrm{n}=149)\end{array}$ & $\begin{array}{l}\text { Comparison } \\
\text { ( } \mathrm{X}^{2} \text { - und } \mathrm{t} \text {-test) }\end{array}$ \\
\hline Duration of the birth in $\mathrm{h}(\mathrm{M} \pm \mathrm{SD})$ & $5.6 \pm 2.6$ & $5.7 \pm 2.5$ & n.s. \\
\hline Interval between administration of pain relief' ${ }^{\prime}$ and birth in $\mathrm{h}(\mathrm{M} \pm \mathrm{SD})$ & $2.9 \pm 3.2$ & $2.2 \pm 2.8$ & n.s. \\
\hline \multicolumn{4}{|l|}{ Side effects } \\
\hline - Nausea (\%) & 59 & 50 & n.s. \\
\hline - Emesis (\%) & 24 & 21 & n.s. \\
\hline - Pathological CTG (\%) & 15 & 13 & n.s. \\
\hline - Uterine atony $(\%)$ & 11 & 8 & n.s. \\
\hline - Administration of oxytocin peripartum (\%) & 43 & 37 & n.s. \\
\hline \multicolumn{4}{|l|}{ Neonatal outcome } \\
\hline - Apgar score at $1 \mathrm{~min}(\mathrm{M} \pm \mathrm{SD})$ & $8.6 \pm 1.0$ & $8.6 \pm 1.1$ & n.s. \\
\hline - Apgar score at $5 \mathrm{~min}(\mathrm{M} \pm \mathrm{SD})$ & $9.3 \pm 0.8$ & $9.5 \pm 0.8$ & n.s. \\
\hline - Apgar score at $10 \min (\mathrm{M} \pm \mathrm{SD})$ & $9.7 \pm 0.6$ & $9.8 \pm 0.4$ & n.s. \\
\hline - Umbilical cord arterial pH $(\mathrm{M} \pm \mathrm{SD})$ & $7.23 \pm 0.09$ & $7.26 \pm 0.08$ & $p=0.02$ \\
\hline - Postnatal monitoring $(\%)$ & 14 & 9 & n.s. \\
\hline - Respiratory assistance (\%) & 11 & 6 & n.s. \\
\hline - Breastfeeding successful (\%) & 95 & 93 & n.s. \\
\hline $\begin{array}{l}\text { Maternal satisfaction with pain relief therapy using a 7-point scale } \\
(M \pm S D)\end{array}$ & $4.9 \pm 1.6$ & $4.8 \pm 1.7$ & n.s. \\
\hline
\end{tabular}

${ }^{1}$ If an opioid was administered several times during parturition, the time of administering the first dose was taken as the starting point.

Table 5 Risk factors for increased administration of regional anesthetic; univariate and multivariate analysis of factors ( $\mathrm{x}^{2}$-test and binary logistic regression).

\begin{tabular}{|c|c|c|c|c|}
\hline RA risk factor & $\begin{array}{l}\text { Univariate } \\
\text { comparison }\left(x^{2}\right)\end{array}$ & $\begin{array}{l}\text { Odds } \\
\text { ratio }\end{array}$ & $\begin{array}{l}95 \% \text {-Cl for } \\
\text { odds ratio }\end{array}$ & $\begin{array}{l}\text { Multivariate } \\
\text { comparison (Wald) }\end{array}$ \\
\hline Pethidine vs. meptazinol (ref) & 0.029 & 2.412 & $1.017-5.723$ & 0.046 \\
\hline Primiparity vs. multiparity (ref) & 0.001 & 1.766 & $0.634-4.915$ & 0.276 \\
\hline Induced birth, yes vs. no (ref) & $<0.001$ & 5.434 & $2.169-13.615$ & $<0.001$ \\
\hline Duration of birth $>7 \mathrm{~h}$ vs. $\leq 7 \mathrm{~h}$ (ref) & $<0.001$ & 9.901 & $3.916-25.031$ & $<0.001$ \\
\hline Antenatal classes yes vs. no (ref) & 0.03 & 0.345 & $0.110-1.082$ & 0.068 \\
\hline Painless birth is desirable, ${ }^{1}$ yes vs. no (ref) & 0.001 & 1.686 & $0.737-3.856$ & 0.216 \\
\hline BMI at the time of delivery in groups ${ }^{2}$ & 0.001 & 1.849 & $1.217-2.809$ & 0.004 \\
\hline
\end{tabular}

${ }^{1}$ Dichotomized mean value for a scale ranging from 1-7, with 1 = "painless birth is entirely desirable" and 7 = "painless birth is not at all desirable", mean: $3.6 ;{ }^{2}$ continuous variation of features in BMl groups (<21, 22-24, 25-29, 30-34, 35-39, $\geq 40)$.

included patients who had provided information on the intensity of pain experienced at each of the three measurement time points.

Results of variance analysis showed that pain relief was significantly stronger following primary RA compared to opioid monotherapy ( $p<0.001)$, although pain was significantly reduced over time with both treatment methods $(\mathrm{p}<0.001)$. Analyzed individually, opioid therapy reduced pain in the first 30 minutes by 2.0 points on the scale (24\%) while primary RA reduced pain by 6.8 points (78\%). In the interval between 30 and 60 minutes after administration, pain increased again by 0.9 points $(15 \%)$ for patients receiving opioid therapy and by 0.8 points ( $42 \%$ ) for patients receiving primary $\mathrm{RA}$. The pain relief achieved with secondary RA was reported as 6.4 points in the first 30 minutes and 6.5 points at 60 minutes, which was comparable with the pain relief obtained with primary RA ( $p>0.05$ respectively).

\section{Maternal and neonatal outcomes after opioid therapy or regional analgesia}

- Table 6 shows duration of the birth, side effects, maternal satisfaction with pain relief therapy and neonatal outcomes following primary RA and opioid monotherapy. The mean duration of the birth and the interval from the time of administering the first dose of analgesia to delivery was longer for women who had primary RA compared to women given opioid therapy $(\mathrm{p}<0.001)$. The duration of the birth was even longer for women who had secondary RA $(9.3 \pm 4.0 \mathrm{~h} ; \mathrm{p}<0.05$ compared with primary RA), with primary and secondary RA administered at statistically comparable intervals prior to delivery $(4.6 \pm 3.8 \mathrm{~h}$ vs. $4.0 \pm 2.5 \mathrm{~h}$; $\mathrm{p}>0.05)$. The rate of oxytocin administration prior to delivery was higher for women with primary RA $(p<0.001)$. There were no statistical differences with regard to any of the other side effects. Mean maternal satisfaction with pain relief therapy was significantly higher after primary RA than after opioid monotherapy ( $\mathrm{p}<0.001)$. Maternal satisfaction with pain relief therapy was $5.1 \pm 1.7$ after secondary RA and thus significantly lower than after primary RA $(\mathrm{p}<0.01)$. Neonatal outcomes were comparable between the different pain relief treatment groups.

\section{Discussion}

This study shows the differences in parenteral administration of the opioids pethidine and meptazinol in routine clinical practice and demonstrates that these can affect the need for additional regional analgesia. 
Table 6 Maternal and neonatal outcomes following opioid monotherapy or primary regional anesthesia; n.s. = not significant.

\begin{tabular}{|c|c|c|c|}
\hline & $\begin{array}{l}\text { Opioid monotherapy } \\
(\mathrm{n}=\mathbf{2 8 1})\end{array}$ & Primary RA $(n=130)$ & $\begin{array}{l}\text { Comparison } \\
\text { ( } \mathrm{x}^{2} \text { - and t-test) }\end{array}$ \\
\hline Duration of the birth in $h(M \pm S D)$ & $5.7 \pm 2.5$ & $7.6 \pm 2.5$ & $<0.001$ \\
\hline Interval between administration of pain relief ${ }^{1}$ and birth in $\mathrm{h}(\mathrm{M} \pm \mathrm{SD})$ & $1.9 \pm 2.2$ & $4.6 \pm 3.8$ & $<0.001$ \\
\hline \multicolumn{4}{|l|}{ Side effects } \\
\hline - Nausea $(\%)$ & 53 & 59 & n.s. \\
\hline - Emesis (\%) & 22 & 30 & n.s. \\
\hline - Pathological CTG (\%) & 14 & 13 & n.s. \\
\hline - Uterine atony (\%) & 9 & 7 & n.s. \\
\hline - Administration of oxytocin peripartum (\%) & 40 & 70 & $<0.001$ \\
\hline - Surgical-vaginal delivery (\%) & 11 & 7 & n.s. \\
\hline \multicolumn{4}{|l|}{ Neonatal outcome } \\
\hline - Apgar score at $1 \mathrm{~min}(\mathrm{M} \pm \mathrm{SD})$ & $8.6 \pm 1.1$ & $8.7 \pm 0.9$ & n.s. \\
\hline - Apgar score at $5 \mathrm{~min}(\mathrm{M} \pm \mathrm{SD})$ & $9.4 \pm 0.8$ & $9.5 \pm 0.7$ & n.s. \\
\hline - Apgar score at $10 \mathrm{~min}(\mathrm{M} \pm \mathrm{SD})$ & $9.8 \pm 0.5$ & $9.8 \pm 0.5$ & n.s. \\
\hline - Umbilical cord arterial $\mathrm{pH}(\mathrm{M} \pm \mathrm{SD})$ & $7.25 \pm 0.09$ & $7.24 \pm 0.08$ & n.s. \\
\hline - Postnatal monitoring (\%) & 11 & 12 & n.s. \\
\hline - Respiratory assistance (\%) & 9 & 9 & n.s. \\
\hline - Breastfeeding successful (\%) & 94 & 94 & n.s. \\
\hline Maternal satisfaction with pain relief therapy using a 7-point scale ( $M \pm S D)$ & $4.8 \pm 1.6$ & $6.1 \pm 1.2$ & $<0.001$ \\
\hline
\end{tabular}

${ }^{1}$ If an opioid was administered several times during parturition, the time when the first dose was administered was taken as the starting point.

In accordance with the rules of observational studies, there were no prior specifications governing the administration or the dosages of the opioids, and the clinicians decided when to administer the opioid and chose the dosage based on the standard rules used in clinical practice. This makes it difficult to compare the opioids from a strictly pharmacological point of view, and it is not clear whether a study with pre-determined rules of administration would have also resulted in the same differences between opioid preparations. The advantage of an observational study, however, is that its results are realistic and clinically relevant. The results should therefore be taken into account in the routine administration of these preparations.

The classification described in the "Initiative on Methods, Measurement and Pain Assessment in Clinical Trials" (IMMPACT) was used to assess the pain relief obtained by the various therapies. According to this classification, a decrease in NRS values by $10-20 \%$ corresponds to rather limited pain relief, a decrease of $\geq 30 \%$ corresponds to moderate relief and a decrease by $\geq 50 \%$ amounts to substantial pain relief [20]. While this classification refers to chronic pain, it is largely consistent with studies measuring acute pain [21].

The relative pain relief was $19 \%$ following the administration of pethidine and $27 \%$ after meptazinol in the first 30 minutes, and $17 \%$ after pethidine and $11 \%$ with meptazinol one hour after administration. Although statistical analysis showed a significant reduction in pain for both opioids, neither of the opioids achieved a moderate level of pain relief as defined in the IMMPACT. The renewed increase in pain between 30 and 60 minutes after administration was around $3 \%$ with pethidine and $22 \%$ with meptazinol. The stronger increase with meptazinol is because this opioid is usually administered intravenously which results in a shorter duration of action. Intravenous administration also results in a faster onset of action, making intravenous analgesia easier to control compared to intramuscular administration, and allowing repeat doses of the opioid to be administered at shorter intervals without running the risk of overdosing. This means that meptazinol is more likely to be administered more often, that the interval between two administrations of meptazinol is shorter than with pethidine and that the last dose of meptazinol can be administered much closer to the time when the baby is delivered than the last dose of pethidine. Some patients received meptazinol until just before giving birth. Nevertheless, the overall dosages of the two opioids per birth were similar, as the individual doses of meptazinol were lower on average than the doses of pethidine. It is common knowledge that labor pain varies considerably in patients and does not always increase linearly [22]. Intravenously administered meptazinol with its faster onset to action and potential for repeated administration to mitigate against peaks of acute pain appears to be better adapted to delivery than pethidine which is administered by intramuscular injection. The potential to give repeated doses of meptazinol allows parturient women to receive pain relief up until the time of delivery. This may also explain the significantly lower rate of additional regional analgesia needed by women receiving meptazinol. A possible reason for the cautious intravenous administration of pethidine in clinical practice could be the risk described in the literature of vasodilation, hypotension and reflectory tachycardia following rapid IV injection of this opioid [10]. No such risk has been described for meptazinol.

The data comparing different parental opioids with respect to maternal satisfaction with therapy is generally unsatisfactory [17]. Our study showed that maternal satisfaction with pethidine therapy was comparable with satisfaction with meptazinol therapy in clinical practice. Satisfaction with both opioids was in the top one third of the 7-point satisfaction rating scale, which is surprising given the limited analgesic efficacy of the opioids. It appears that the degree of analgesia achieved is not the sole determinant for patients' satisfaction with treatment. It is conceivable that other factors such as simple and rapid administration, low invasiveness and few side effects or even just the attention and care given to the patient have a positive impact on the patient's satisfaction with the treatment she received. The differences in the administration of the opioids do not appear to have had any relevant impact on patient satisfaction with treatment.

In this study, the side effects of the opioids on mother and child were largely comparable for both opioids. The differences be- 
tween pethidine and meptazinol postulated in other studies with regard to postnatal Apgar scores [16], maternal nausea and emesis [23] and inhibitory effect on oxytocin secretion [24,25] were not found in our study. Only postnatal umbilical cord arterial $\mathrm{pH}$ was found to be lower following pethidine therapy, although the averages for both opioids were within normal ranges and the difference was therefore not clinically relevant. Our results however partly support the findings of other studies which reported a stronger respiratory depression effect following pethidine administration $[15,16]$. This difference is caused by the different receptor affinities of the two opioids - as pethidine binds more strongly to $\mu 2$ opioid receptors binding this is assumed to result in respiratory depression - and the longer elimination half-time of pethidine in neonates $[13,14]$.

Another difference between the two opioids was the significantly higher rate of secondary RA following pethidine therapy. This effect has not been previously described in the literature and confirms the hypothesis of better pain relief with meptazinol. Multivariate tests using binary logistic regression showed that the risk of RA following pethidine treatment was more than double compared to that for meptazinol therapy. Regression analysis found that other significant peripartum predictors for RA were longer duration of birth and induction of labor. But it is not clear whether the longer duration of birth was a side effect of RA [26], or whether complicated and prolonged births led to an increased need for RA [27]. The increased risk for RA after labor was induced is probably due to the fact that induction of labor can result in more painful and less effective uterine contractions compared to spontaneous induction of labor [28] and therefore requires more pain relief.

While random sampling of all pethidine and meptazinol patients $(n=319)$ showed significant differences with regard to factors promoting RA such as induction of labor and S/P cesarean section (cf. $\bigcirc$ Table 1), when all patients who received opioid treatment followed by secondary RA $(n=38)$ were analyzed with regard to all tested RA predictors, no differences were found except for the choice of opioid ( $p>0.05$ respectively). This confirms the supposition that pethidine therapy itself was decisive for the increased demand for RA.

The study also shows that, based on clinical observation, regional analgesia also offers effective, satisfactory and safe pain relief peripartum. Compared with parenteral opioid therapy, the efficacy of pain relief obtained with RA was found to be significantly higher. While opioids did not achieve even moderate pain relief as measured by IMMPACT as they only reduced pain by $24 \%$ in the first 30 minutes and by $13 \%$ over a one hour observation period, RA achieved a substantial pain reduction of $78 \%$ after 30 minutes and $69 \%$ over 60 minutes. The results are consistent with those in the current literature [8]. Maternal satisfaction with pain therapy was highest following primary RA, followed by secondary RA and finally after opioid monotherapy. That use of RA as the analgesia method is associated with higher levels of patient satisfaction with treatment has been noted previously in the literature $[6,7]$. That secondary RA resulted in a lower patient satisfaction compared to primary RA has not been previously described and the reason for this is probably that the prior, less effective opioid therapy contributed to the poorer assessment of secondary RA.

Typical side effects of RA reported in the literature are prolonged delivery, higher rates of surgical vaginal deliveries, and intrapartum oxytocin administration $[8,29]$. All of these could be due to lower uterine performance. Our results also showed longer deliv- ery times with RA compared to opioid treatment. But it is debatable whether RA is the reason for the prolonged birth or whether women with prolonged delivery times per se demand more RA in consequence. That fact that the period from analgesic intervention to birth is significantly longer for RA compared to opioid treatment would appear to indicate that RA prolongs delivery. The longest births were those where women initially received opioid therapy and secondary RA, although in these cases opioid administration always preceded RA administration. It is therefore also conceivable that these births were prolonged beyond the sole impact caused by RA. After all, they did provide enough time for several different treatment methods to be used. Alternative explanations for prolonged delivery include cervical dystocia or cephalopelvic disproportion [30]. In our study, the rate of oxytocin administrations peripartum was also increased after RA. The number of surgical-vaginal deliveries was comparable for RA and opioid treatment. The rate of cesarean sections for the respective treatments was not analyzed, as patients who required secondary cesarean section were excluded from the study. This was necessary to avoid differences in samples to the detriment of the RA group, as early RA is indicated particularly in women who have more risk factors for secondary cesarean section [31]. Randomized studies have already confirmed that RA does not increase the rate of cesarean sections $[8,9]$.

This study was an observational study. In contrast to a randomized double-blind study, the advantage of an observational study is that it offers the opportunity to investigate treatments carried out in a real environment with decisions taken based on routine clinical considerations. At the same time, the study design can be a source of error. It is important to be aware of differences between the groups ( $\bullet$ Table 1 ). Overall, the patients who had pethidine therapy had more factors which could result in greater severity of pain during labor. On the one hand, the higher number of patients requiring induction of labor in this group could also increase overall pain levels [28]. On the other hand, this group also included a significantly higher number of women with a history of previous cesarean section. This means that the percentage of women giving birth to their second child for whom this was the first vaginal delivery, was significantly higher $(\mathrm{p}<0.01)$. In the pain analysis these women were evaluated in the same way as primipara, who in turn regularly described the birth as more painful than multipara did [32]. A comparison of the groups receiving opioid monotherapy with the group of women who had primary RA showed that the RA group had more pain-enhancing factors such as primiparity and induction of labor $[28,32]$. There are also indications that strong weight gain in and high maternal and fetal weight at birth result in stronger labor pains [22]. The higher maternal BMI in the RA group therefore may also have resulted in greater severity of pain. The rate of women with breech presentation was also higher in the RA group, but stronger pain in women with breech presentation has not been described in the literature. However, the initial NRS pain prior to any intervention was comparable between groups. The unequal distribution in factors associated with higher affinity to pain did not appear to have any effect in our patients.

\section{Conclusion for Clinical Practice}

$\nabla$

The clinical evaluation of parenteral opioids showed an advantage for intravenously administered meptazinol. Meptazinol administration resulted in pain relief and patient satisfaction with 
pain therapy which was comparable to that for pethidine; however, meptazinol administration was associated with a lower need to escalate analgesia though secondary regional anesthesia. Overall, the analgesic efficacy of parenteral opioid administration lagged far behind that of regional analgesics. The group with the highest satisfaction rate regarding pain relief therapy consisted of those women who had primary RA.

\section{Conflict of Interest}

$\nabla$

None.

\section{References}

1 Jones L, Othman M, Dowswell T et al. Pain management for women in labour: an overview of systematic reviews. Cochrane Database Syst Rev 2012; 3: CD009234

2 Ward ME. Acute pain and the obstetric patient: recent developments in analgesia for labor and delivery. Int Anesthesiol Clin 1997; 35: 83-103

3 Reynolds $F$. Labour analgesia and the baby: good news is no news. Int J Obstet Anesth 2011; 20: 38-50

4 Philipsen T, Jensen $\mathrm{NH}$. Epidural block or parenteral pethidine as analgesic in labour; a randomized study concerning progress in labour and instrumental deliveries. Eur J Obstet Gynecol Reprod Biol 1989; 30: 27-33

5 Jain S, Arya VK, Gopalan $S$ et al. Analgesic efficacy of intramuscular opioids versus epidural analgesia in labor. Int J Gynaecol Obstet 2003; 83: $19-27$

6 Mansoori S, Adams S, Cheater FM. Choice of analgesia in labour on neonatal outcomes, delivery and maternal satisfaction with pain relief. Clin Effect Nurs 2000; 4: 11-19

7 Bricker L, Lavender T. Parenteral opioids for labor pain relief: a systematic review. Am J Obstet Gynecol 2002; 186 (5 Suppl. Nature): S94S109

8 Anim-Somuah M, Smyth RM, Jones L. Epidural versus non-epidural or no analgesia in labour. Cochrane Database Syst Rev 2011; 12: CD000331

9 Sharma SK, Alexander JM, Messick G et al. Cesarean delivery: a randomized trial of epidural analgesia versus intravenous meperidine analgesia during labor in nulliparous women. Anesthesiology 2002; 96: 546551

10 Sanofi-Aventis Deutschland GmbH. Fachinformation Dolantin ${ }^{\circledR}, 2014$. Online: http://www.fachinfo.de/pdf/000632; Stand: 20.07.2016

11 Rote Liste 2015. Arzneimittelverzeichnis für Deutschland (einschließlich EU-Zulassungen und bestimmter Medizinprodukte). 55. Aufl. Frankfurt/Main: Rote Liste Service; 2015

12 Friebe-Hoffmann U, Beck L. Medikamentöse Analgesie in der Geburtshilfe. Gynäkologe 2007; 40: 190-193

13 Caldwell J, Wakile LA, Notarianni LJ et al. Maternal and neonatal disposition of pethidine in childbirth-a study using quantitative gas chromatography-mass spectrometry. Life Sci 1978; 22: 589-596
14 Biosyn. Fachinformationen Meptid ${ }^{\circledR}$, 2012. Online: http://www.biosyn. de/uploads/media/Meptid_FI_2012-12.pdf; Stand: 20.07.2016

15 de Boer FC, Shortland D, Simpson RL et al. A comparison of the effects of maternally administered meptazinol and pethidine on neonatal acidbase status. Br J Obstet Gynaecol 1987; 94: 256-261

16 Nicholas AD, Robson PJ. Double-blind comparison of meptazinol and pethidine in labour. Br J Obstet Gynaecol 1982; 89: 318-322

17 Ullman R, Smith LA, Burns E et al. Parenteral opioids for maternal pain relief in labour. Cochrane Database Syst Rev 2010; 9: CD007396

18 Lowe NK. The pain and discomfort of labor and birth. J Obstet Gynecol Neonatal Nurs 1996; 25: 82-92

19 Amara S, Singer J, Stepan H, Jank A, Philippi-Höhne C. Qualität der peripartalen Schmerztherapie mit niedrigpotenten Opioiden. In: Thiery J, Beck-Sickinger AG, Arendt T, eds. 11th Leipzig Research Festival for Life Science. Abstract Book. Leipzig: 2012

20 Dworkin RH, Turk DC, Wyrwich KW et al. Interpreting the clinical importance of treatment outcomes in chronic pain clinical trials: IMMPACT recommendations. J Pain 2008; 9: 105-121

21 Cepeda MS, Africano JM, Polo R et al. What decline in pain intensity is meaningful to patients with acute pain? Pain 2003; 105: 151-157

22 Melzack R, Kinch R, Dobkin P et al. Severity of labour pain: influence of physical as well as psychologic variables. Can Med Assoc J 1984; 130 : 579-584

23 Morrison CE, Dutton D, Howie H et al. Pethidine compared with meptazinol during labour. A prospective randomised double-blind study in 1100 patients. Anaesthesia 1987; 42: 7-14

24 Russell JA, Leng G, Coombes JE et al. Pethidine (meperidine) inhibition of oxytocin secretion and action in parturient rats. Am J Physiol 1991; 261 (2 Pt 2): R358-R368

25 Clarke G, Wright DM. A comparison of analgesia and suppression of oxytocin release by opiates. Br J Pharmacol 1984; 83: 799-806

26 Halpern SH, Abdallah FW. Effect of labor analgesia on labor outcome. Curr Opin Anaesthesiol 2010; 23: 317-322

27 Jeschke E, Ostermann T, Dippong $N$ et al. Identification of maternal characteristics associated with the use of epidural analgesia. J Obstet Gynaecol 2012; 32: 342-346

28 NICE. Induction of Labor. NICE clinical guideline 70, 2008. Online: https://www.nice.org.uk/guidance/CG70/chapter/Introduction; Stand: 20.07.2016

29 Liu EH, Sia AT. Rates of caesarean section and instrumental vaginal delivery in nulliparous women after low concentration epidural infusions or opioid analgesia: systematic review. BMJ 2004; 328: 1410

30 Schneider $H$. Mütterliche und kindliche Risiken der protrahierten Geburt. Gynäkologe 1998; 31: 734-737

31 DGAI; BDA; DGGG. Durchführung von Analgesie- und Anästhesieverfahren in der Geburtshilfe. 2. überarbeitete Empfehlungen der Deutschen Gesellschaft für Anästhesiologie und Intensivmedizin und des Berufsverbandes Deutscher Anästhesisten in Zusammenarbeit mit der Deutschen Gesellschaft für Gynäkologie und Geburtshilfe. Anästh Intensivmed 2009; 50: 183-189

32 Sheiner E, Sheiner EK, Shoham-Vardi I. The relationship between parity and labor pain. Int J Gynaecol Obstet 1998; 63: 287-288 